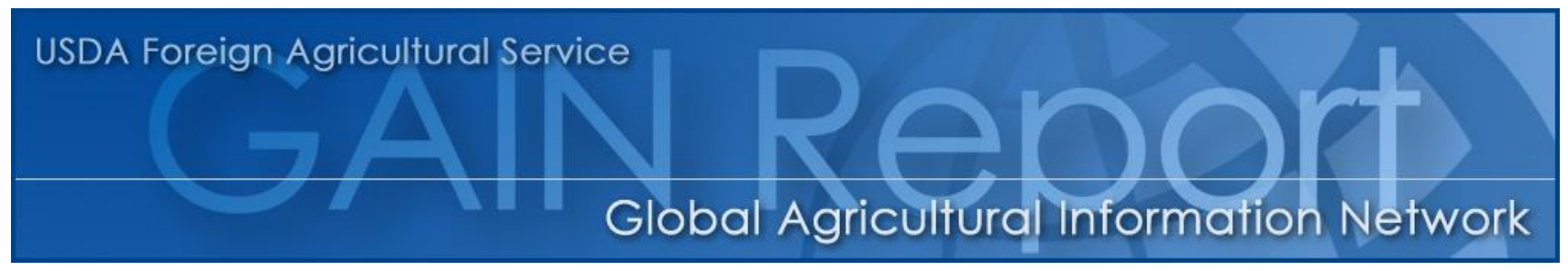

THIS REPORT CONTAINS ASSESSMENTS OF COMMODITY AND TRADE ISSUES MADE BY USDA STAFF AND NOT NECESSARILY STATEMENTS OF OFFICIAL U.S. GOVERNMENT POLICY

Required Report - public distribution

Date: $9 / 29 / 2016$

GAIN Report Number: MX3034

\title{
Mexico
}

\section{Sugar Semi-annual}

\section{6}

\author{
Approved By: \\ Lashonda V. McLeod \\ Prepared By: \\ Dulce Flores
}

\section{Report Highlights:}

Mexican sugar production for marketing year 2016/17 is forecast at 6.6 million metric tons raw-value (MMT-RV). Sugar production for MY 2015/16 is revised downward to 6.4 MMT-RV. The sugar export forecast for MY 2016/17 is 1.2 MMT-RV. Total sugar export estimate for MY 2015/16 is 1.3 MMT-RV, where exports to the United States under the suspension agreements are expected at 1,178,116 MT-RV. The high fructose corn syrup (HFCS) import forecast for MY 2016/17 is expected to be similar to MY 2015/16 imports, or close to 1.0 MMT dry basis. 


\section{Commodities:}

Sugar Cane for Centrifugal

Sugar, Centrifugal

\section{PRODUCTION:}

\section{Sugar}

The Mexican sugar industry forecast for sugar production for marketing year (MY) 2016/17

(October/September) is expected to be slightly higher compared to MY 2015/16 production levels, since there is potential for higher production as rainfall has been beneficial to most area planted. According to the Mexican National Committee for the Sustainable Development of Sugar Cane (CONADESUCA), sugar production is forecast at about 6.6 million metric tons raw value (MMT-RV) for MY 2016/17. But final production will depend on appropriate cultivation practices, such as application of fertilizers, pesticides, crop rotation, and pruning as well as timely maintenance of sugar mills, weather throughout the growing season, and harvest conditions. Since the nine remaining government mills have already been sold to the private sector, it is expected that for MY 2016/17 the sugar sector will be more consolidated as an industry.

According CONADESUCA, the last estimate for sugar production for MY 2015/16 was 6.48 MMTRV, slightly higher compared to their first estimate of 6.40 MMT-RV. Fifty mills operated throughout the country during MY 2015/16. According to official estimates, cane yields for MY 2015/16 were about 69.5 tons/hectare, mill yields were at 11.29 percent, area harvested was 778,930 hectares, and milled cane was 54,188,609 MT. The Post/New sugar production estimate for MY 2014/15 remains unchanged. According to official sources, Mexico is not producing organic sugar on a commercial basis. As previously reported, virtually all sugar cane goes to the production of centrifugal sugar. There is some production of ethylic alcohol as a by-product. Mills operate between November and June to coincide with the cane harvest. The Post/New estimate of cane to be processed for MY 2016/17 is 55.0 MMT. Sugarcane production for MY 2014/15 remains unchanged.

\section{High Fructose Corn Syrup}

The Mexican high fructose corn syrup (HFCS) industry believes it will continue producing HFCS for MY 2015/16 at almost the same levels as in MY 2014/15 which was 498,820 MT dry basis.

CONADESUCA estimates HFCS domestic production for MY 2015/16 at 517,838 MT dry basis. These volumes are almost the maximum capacity of the industry. Industry members indicate that there is no additional HFCS manufacturing capacity being built or expanded in Mexico. Sources report that as long as HFCS prices remain competitive, it is easier and more financially prudent to import the remainder of HFCS demand. Even as sugar prices have been somewhat high, HFCS consumption is not expected to increase much due to import costs. It is expected that the bottling industry will continue to have similar HFCS consumption as in the past. It is important to note that due to the depreciation of the Mexican peso against the U.S. dollar, imports of HFCS will become more expensive. 
The Mexican HFCS industry produces fructose with domestic and imported U.S. yellow corn. According to the Industry of Food Derivatives and Chemical of Corn

(IDAQUIM), the group that represents HFCS producers, the industry consumes about two million tons of yellow corn of which 80 to 90 percent is imported.

\section{CONSUMPTION:}

\section{Sugar}

Assuming current pricing trends for sugar and fluctuating exchange rates, the sugar industry is expecting sugar consumption to grow according to the population growth rate for MY 2016/17. However, due to the sugar quota implemented within the suspension agreements, more sugar might be available in the domestic market. Based on market intelligence, the Post/New domestic sugar consumption estimate for MY 2016/17 is revised upward from previous estimates, due to an expected higher demand mainly from the carbonated soft drink companies. Consumption will also depend on the substitution of sugar with HFCS.

The Post/New domestic sugar consumption estimate for MY 2015/16 is revised upward from previous estimates reflecting higher demand of sugar. There is more sugar available in the domestic market than previously expected as the industry is selling to the domestic market rather than the international market due to good prices. The Post/New domestic sugar consumption estimate for MY 2014/15 was updated based on official sources.

\section{High Fructose Corn Syrup}

Substitution between HFCS and sugar has been increasing slowly, as it seems that industries have been using HFCS in similar amounts over the last two years, including the largest user of HFCS, soda bottlers. Trends for MY 2015/16 indicate growth in HFCS consumption of 1.44 MMT dry basis, a 2.6 percent increase over MY 2014/15 consumption. Growth in MY 2014/15 was 5.2 percent over MY 2013/14. This volume of HFCS still represents about 25.4 percent of total domestic sweeteners consumption. HFCS consumption depends on domestic sugar prices, imported corn and HFCS prices, and on current exchange rates.

\section{Sugar Wholesale Prices}

The Secretariat of Economy (SE), through the National Market Information Service (SNIIM), reports sugar prices on a monthly basis as delivered to different cities in Mexico from different mills. According to the industry, higher prices after the month of April/May 2016 reflect the end of the harvesting season. In fact, higher prices have affected bottling companies who are accommodating soda prices for the final consumer. Higher prices after July 2016 seem to be speculation from the part of some mills that are selling smaller volumes to the market. In November sugar prices have a tendency to go downward reflecting the beginning of a new cycle; however, with the new organization of the market, where all the mills are now private, it is uncertain how the market and the sugar prices will respond. The industry can now sell sugar at their pace. 


\section{TRADE:}

\section{Sugar}

In December 2014, the United States and Mexico signed agreements to avoid the imposition of antidumping (AD) and countervailing duties (CVD) on Mexican sugar imported into the United States. The suspension agreements manage the volume and price of all Mexican sugar imported into the United States. For further information about the history and content of the suspension agreements, please see previous annual GAIN report (MX6016 Sugar Annual Report). These agreements are currently under review by both parties for possible adjustments. There is concern from the Mexican sugar industry regarding the amount of the sugar quota that was allotted to Mexico on May 17, 2016, and regarding the polarity requirements for that quota. Talks between both governments and the industry are currently underway to resolve these issues under the Sugar Agreement.

Since there is no official data yet on exports for MY 2016/17, based on different sources, Post/New sugar export forecast is revised downward to 1.2 MMT-RV from previous estimates, based on the expectations for the quota allotment of sugar to be exported to the United States. The amount of total quota of sugar to be exported to the United States announced on August 30, 2016, in the Mexican Official Gazette (Diario Oficial) for MY 2016/17 is 870,688.94 MT-RV, which represents a 70 percent of the total amount to be exported. Export data is tentative and will tend to change depending on production, U.S. and international sugar and sweeteners (HFCS) prices, and exchange rates.

The Post/New sugar export estimate for MY 2015/16 is revised upward from previous estimates to 1.3 MMT-RV, based on CONADESUCA's recent export data. According to sources, the industry still plans to export to the United States about 1,178,116 MT-RV, under the sugar agreement. As of August 14, 2016, according to CONADESUCA, Mexico has exported to the U.S. market about 1,032,032 MTRV. Sugar exports to other countries will be lower than expected at 158,000 MT-RV, as the industry will be selling more sugar to the domestic market now that prices are higher. On September 22, 2016, an additional quota of 54,431.10 MT- RV was announced by the government to export to the United States that must be shipped by September 30, 2016. This sugar should be non-refined and of low polarity.

The Mexican peso depreciation against the U.S. Dollar has made exports more profitable for Mexico and international prices for sugar seem to be better now than the previous months. However, since agrochemicals are imported, in the long term these products will become more expensive. The Post/New sugar export estimate for MY 2014/15 is revised slightly downward from previous estimates based on official information from CONADESUCA.

The Post/New sugar import forecast for MY 2016/17 is estimated at 10,000 MT-RV as domestic supplies are expected to remain adequate. The Post/New sugar import estimates for MY 2015/16 are revised downward from previous estimates as changes to the re-export program (IMMEX) are expected to lower imports. Earlier, when IMMEX was in place, a large portion of imports were used to cover the needs of the Mexican Sugar Re-export Program industries (IMMEX). As previously reported, in early 2015 the SE submitted a proposal to modify the IMMEX program to Mexico's equivalent of the Office of Management and Budget, COFEMER. This proposal was approved and states that as of February 5, 2016, IMMEX-certified companies can only import sugar if that sugar does not benefit from the U.S. 
Sugar Re-export Program. As a result, "Maquila" companies that have used U.S. sugar from the Reexport Program will need to find alternate sources to supply their needs. Some sources believe there will be no issues in sourcing Mexican sugar for their operations, while others believe some Maquila companies will close operations. Sugar import estimates for MY 2014/15 are revised upward to 181,000 MT-RV from previous estimates. A large portion of these imports were likely used to cover the needs of the IMMEX industries.

Sugar use under the "other disappearance" category is mainly for the IMMEX program. The Post/New forecast for MY 2016/17 for sugar use under IMMEX is revised upward from previous estimates to 318,000 MT-RV according to sources. The Maquila industries are using slightly less imported sugar as they were using before the IMMEX change of rules. The Post/New estimate for MY 2015/16 for sugar use under IMMEX is also revised upward from previous estimates based on market intelligence. The Post/New estimate for sugar use under IMMEX for MY 2014/15 is updated based on CONADESUCA's report.

\section{High Fructose Corn Syrup Imports}

HFCS imports for MY 2016/17 are expected to be similar to MY 2015/16 imports, or close to 1.0 MMT dry basis. However, some industry members believe that imports for MY 2016/17 could be slightly lower than expected due to the impact that the Mexican peso depreciation against the U.S. dollar will have on prices. According to CONADESUCA, imports of HFCS for MY 2015/16 were 966,974 MT dry basis. HFCS imports for MY 2014/15 were at 982,037 MT dry basis.

\section{STOCKS:}

The Post/New sugar ending stocks for MY 2016/17 are expected to end higher than previously reported, based on lower sugar exports and higher sugar production expectations. The Post/New sugar ending stock forecast for MY 2015/16 is revised downward from previous estimates, but is still considered high due to lower sugar exports. Sugar ending stocks for MY 2014/15 remain almost unchanged from previous estimates.

\section{POLICY:}

\section{Sale of State Owned Sugar Mills}

As previously reported, in June 2015, four mills were sold by the government to private owners, and in December 2015, the government sold three additional mills. On June 13, 2016, Mexico's Service of Administration and Disposition of Assets (SAE) published the public tender of the last two state-owned sugar mills managed by the Fund of Expropriated Sugar Sector Businesses (FEESA), which was created to administer the government expropriated sugar mills. The mills were El Potrero and San Miguelito; both are located in the State of Veracruz. In August 2016, both mills were sold to Group Beta San Miguel. With this last sale, the Mexican government has sold all the mills that were under its administration.

\section{Ethanol Issues}


The current version of Mexico's Biofuels Law was published in the Diario Oficial on February 1, 2008. As previously reported, the Law contains a comprehensive biofuels policy that promotes ethanol production from different agricultural commodities. There are provisions within the Sugar Law that contain overall goals focused on the possibility of producing ethanol. Eight years later, Mexico has not formally introduced ethanol into its commercial gasoline mix. Price fluctuations in both the oil and ethanol markets and the lack of an established supply chain have prevented the country from fully establishing its "clean-fuel" strategy. Mexico's state-run oil company, Petroleos Mexicanos (PEMEX) is still working with the winners of last year's bidding process and is scheduled to begin changes on its distribution and storage infrastructure to be able to receive ethanol that, per the contracts signed, will be mixed with its Magna brand gasoline at a 5.8 percent (E6) level. Still, some of the companies that won bids have yet to begin ethanol production, so no immediate ethanol deliveries are expected in the short term.

Additionally, the Mexican government moved some of the energy reform dates affecting fuel trade forward. First was the authorization to sell gasoline under a brand different from PEMEX and then the authorization to import gasoline, so private companies are now allowed to import gasolines (some of which will be already mixed with ethanol) and sell them in Mexico using their own brand. As of September 15, 2016, the Mexican Ministry of Energy (SENER) has issued 120 gasoline import permits which totaled a maximum of 30 billion gallons of gasoline. The only lock remaining on the fuel sector is the one related to price, which is currently determined by the Mexican Ministry of Finance (SHCP) until 2018, when prices will be finally liberated, although media has reported that a discussion is currently underway to move that liberalization forward, maybe to the start of 2017.

In August 2016, the Energy Regulatory Commission (CRE) published new gasoline specifications in the Mexican Official Norm, NOM-016 allowing for the first time the use of up to 5.8 percent of ethanol as an oxygenate in gasoline. However, ethanol is not permitted to be used in gasoline in the metropolitan areas of Mexico City, Guadalajara, and Monterrey. The new NOM enters into force on October 29, 2016.

\section{STATISTICAL TABLES}

Table 1. Mexico: Centrifugal Sugar PS\&D

\begin{tabular}{|l|r|r|r|r|r|r|}
\hline \multirow{2}{*}{$\begin{array}{l}\text { Sugar, Centrifugal } \\
\text { Market Begin Year }\end{array}$} & \multicolumn{2}{|c|}{$\mathbf{2 0 1 4 / 2 0 1 5}$} & \multicolumn{2}{c|}{$\mathbf{2 0 1 5 / 2 0 1 6}$} & \multicolumn{2}{c|}{$\mathbf{2 0 1 6 / 2 0 1 7}$} \\
\cline { 2 - 7 } Mexico & \multicolumn{2}{|c|}{ Oct 2014 } & \multicolumn{2}{|c|}{ Oct 2015 } & \multicolumn{2}{c|}{ Oct 2016 } \\
\cline { 2 - 7 } & USDA Official & New Post & USDA Official & New Post & USDA Official & New Post \\
\hline Beginning Stocks & 881 & 881 & 860 & 859 & 1440 & 1038 \\
\hline Beet Sugar Production & 0 & 0 & 0 & 0 & 0 & 0 \\
\hline Cane Sugar Production & 6344 & 6344 & 6555 & 6484 & 6466 & 6675 \\
\hline Total Sugar Production & 6344 & 6344 & 6555 & 6484 & 6466 & 6675 \\
\hline
\end{tabular}




\begin{tabular}{|l|r|r|r|r|r|r|}
\hline Raw Imports & 0 & 0 & 0 & 0 & 0 & 0 \\
\hline Refined Imp.(Raw Val) & 161 & 181 & 74 & 45 & 10 & 10 \\
\hline Total Imports & 161 & 181 & 74 & 45 & 10 & 10 \\
\hline Total Supply & 7386 & 7406 & 7489 & 7388 & 7916 & 7723 \\
\hline Raw Exports & 0 & 0 & 0 & 0 & 0 & 0 \\
\hline Refined Exp.(Raw Val) & 1545 & 1517 & 1188 & 1336 & 1606 & 1250 \\
\hline Total Exports & 1545 & 1517 & 1188 & 1336 & 1606 & 1250 \\
\hline Human Dom. Consumption & 4638 & 4672 & 4591 & 4696 & 4661 & 4760 \\
\hline Other Disappearance & 343 & 358 & 270 & 318 & 270 & 318 \\
\hline Total Use & 4981 & 5030 & 4861 & 5014 & 4931 & 5078 \\
\hline Ending Stocks & 860 & 859 & 1440 & 1038 & 1379 & 1395 \\
\hline Total Distribution & 7386 & 7406 & 7489 & 7388 & 7916 & 7723 \\
\hline & & & & & \\
\hline (1000 MT) & & & & & \\
\hline
\end{tabular}

Table 2. Mexico: Sugar Cane for Centrifugal PS\&D

\begin{tabular}{|l|r|r|r|r|r|r|}
\hline \multirow{2}{*}{$\begin{array}{l}\text { Mugar Cane for Centrifugal } \\
\text { Mexico }\end{array}$} & \multicolumn{2}{|c|}{$\mathbf{2 0 1 4 / 2 0 1 5}$} & \multicolumn{2}{c|}{$\mathbf{2 0 1 5 / 2 0 1 6}$} & \multicolumn{2}{c|}{$\mathbf{2 0 1 6 / 2 0 1 7}$} \\
\cline { 2 - 7 } & \multicolumn{2}{|c|}{ Nov 2014 } & \multicolumn{2}{c|}{ Nov 2015 } & \multicolumn{2}{c|}{ Nov 2016 } \\
\cline { 2 - 7 } & USDA Official & New Post & USDA Official & New Post & USDA Official & New Post \\
\hline Area Planted & 820 & 820 & 824 & 824 & 836 & 836 \\
\hline Area Harvested & 783 & 783 & 801 & 780 & 800 & 800 \\
\hline Production & 53601 & 53601 & 54275 & 54188 & 55000 & 55000 \\
\hline Total Supply & 53601 & 53601 & 54275 & 54188 & 55000 & 55000 \\
\hline Utilization for Sugar & 53601 & 53601 & 54275 & 54188 & 55000 & 55000 \\
\hline Utilization for Alcohol & 0 & 0 & 0 & 0 & 0 & 0 \\
\hline Total Utilization & 53601 & 53601 & 54275 & 54188 & 55000 & 55000 \\
\hline \multicolumn{7}{|l}{} \\
\hline
\end{tabular}

\begin{tabular}{|l|l|l|l|l|l|l|}
\hline \multicolumn{7}{|c|}{ Table 3. Mexico: Average Wholesale Sugar Prices in Mexico City } \\
MX Pesos per 50 Kilograms - Bulk (CIF Prices) \\
\hline MONTH & STANDARD & & \multicolumn{2}{c|}{ REFINED } & \\
\hline & $\mathbf{2 0 1 5}$ & $\mathbf{2 0 1 6}$ & Percent & $\mathbf{2 0 1 5}$ & $\mathbf{2 0 1 6}$ & Percent \\
\hline & & & Change & & & Change \\
\hline January & 387.25 & 530.75 & 37.05 & 498.42 & 591.25 & 18.62 \\
\hline February & 378.50 & 560.75 & 48.15 & 492.92 & 602.50 & 22.23 \\
\hline March & 370.60 & 552.80 & 49.16 & 486.07 & 598.00 & 23.02 \\
\hline April & 382.63 & 587.50 & 53.32 & 480.84 & 613.75 & 27.90 \\
\hline May & 382.67 & 585.00 & 52.87 & 480.56 & 615.00 & 27.97 \\
\hline
\end{tabular}




\begin{tabular}{|l|l|l|l|l|l|l|}
\hline June & 450.80 & 603.75 & 33.92 & 516.33 & 643.75 & 24.67 \\
\hline July & 458.00 & 647.50 & 41.37 & 504.17 & 691.25 & 37.10 \\
\hline August & 477.50 & 710.60 & 48.81 & 510.42 & 744.00 & 45.76 \\
\hline September & 570.80 & 715.00 & 25.26 & 591.33 & 754.58 & 27.60 \\
\hline October & 568.75 & & & 590.00 & & \\
\hline November & 551.25 & & & 586.67 & & \\
\hline December & 540.00 & & \multicolumn{5}{|l|}{589.00} & & \\
\hline Source: Servicio Nacional de Información de ercados SNIIM-ECONOMIA \\
\hline
\end{tabular}

\begin{tabular}{|l|l|l|l|l|}
\hline \multicolumn{5}{|c|}{ Table 4. Mexico: Monthly Exchange Rate } \\
Averages for 2013-2016 \\
MX Pesos per U.S. \$1.00 \\
\hline & $\mathbf{2 0 1 3}$ & $\mathbf{2 0 1 4}$ & $\mathbf{2 0 1 5}$ & $\mathbf{2 0 1 6}$ \\
\hline January & 12.71 & 13.20 & 14.68 & 18.02 \\
\hline February & 12.69 & 13.28 & 14.92 & 18.47 \\
\hline March & 12.54 & 13.22 & 15.21 & 17.69 \\
\hline April & 12.21 & 13.29 & 15.22 & 17.49 \\
\hline May & 12.95 & 12.93 & 15.26 & 18.09 \\
\hline June & 12.94 & 12.99 & 15.46 & 18.12 \\
\hline July & 12.77 & 12.97 & 15.92 & 18.58 \\
\hline August & 12.89 & 13.14 & 16.50 & 18.47 \\
\hline September & 13.08 & 13.21 & 16.85 & $18.87 *$ \\
\hline October & 13.00 & 13.47 & 16.58 & \\
\hline November & 13.07 & 13.59 & 16.63 & \\
\hline December & 13.00 & 14.44 & 17.03 & \\
\hline Annual Avg & $\mathbf{1 2 . 7 6}$ & $\mathbf{1 3 . 2 9}$ & $\mathbf{1 5 . 8 5}$ & \\
\hline *As of third week of September 2016 & & \\
\hline Source: Mexican Federal Register \\
Note: Monthly rates are averages of daily exchange rates from the Banco de Mexico
\end{tabular}

\section{For More Information}

FAS/Mexico Web Site: We are available at http://www.mexico-usda.com.mx or visit the FAS headquarters' home page at www.fas.usda.gov for a complete selection of FAS worldwide agricultural reporting.

Useful Mexican Web Sites: Mexico's equivalent of the U.S. Department of Agriculture (SAGARPA) can be found at www.sagarpa.gob.mx, the equivalent of the U.S. Department of Commerce (SE) can be found at www.economia.gob.mx , and the equivalent of the U.S. Food and Drug Administration (SALUD) can be found at www.salud.gob.mx. These web sites are mentioned for the reader's convenience but USDA does not in any way endorse, guarantee the accuracy of, or necessarily concur with the information contained in the aforementioned sites. 


\section{Other Relevant FAS/Mexico GAIN Reports:}

\begin{tabular}{|l|l|c|}
\hline $\begin{array}{l}\text { Report } \\
\text { Number }\end{array}$ & \multicolumn{1}{|c|}{ Subject } & Date Submitted \\
\hline MX6030 & Mexico Announces Maximum Sugar Export Quota to the United States & $08 / 31 / 2016$ \\
\hline \hline MX6026 & Mexico Puts Last Two State-Owned Sugar Mills Up for Sale & $06 / 13 / 2016$ \\
\hline MX6016 & Sugar Annual Report & $04 / 15 / 2016$ \\
\hline \hline MX6012 & Mexico Announces Increased Sugar Export Quota to the United States & $04 / 05 / 2016$ \\
\hline
\end{tabular}

